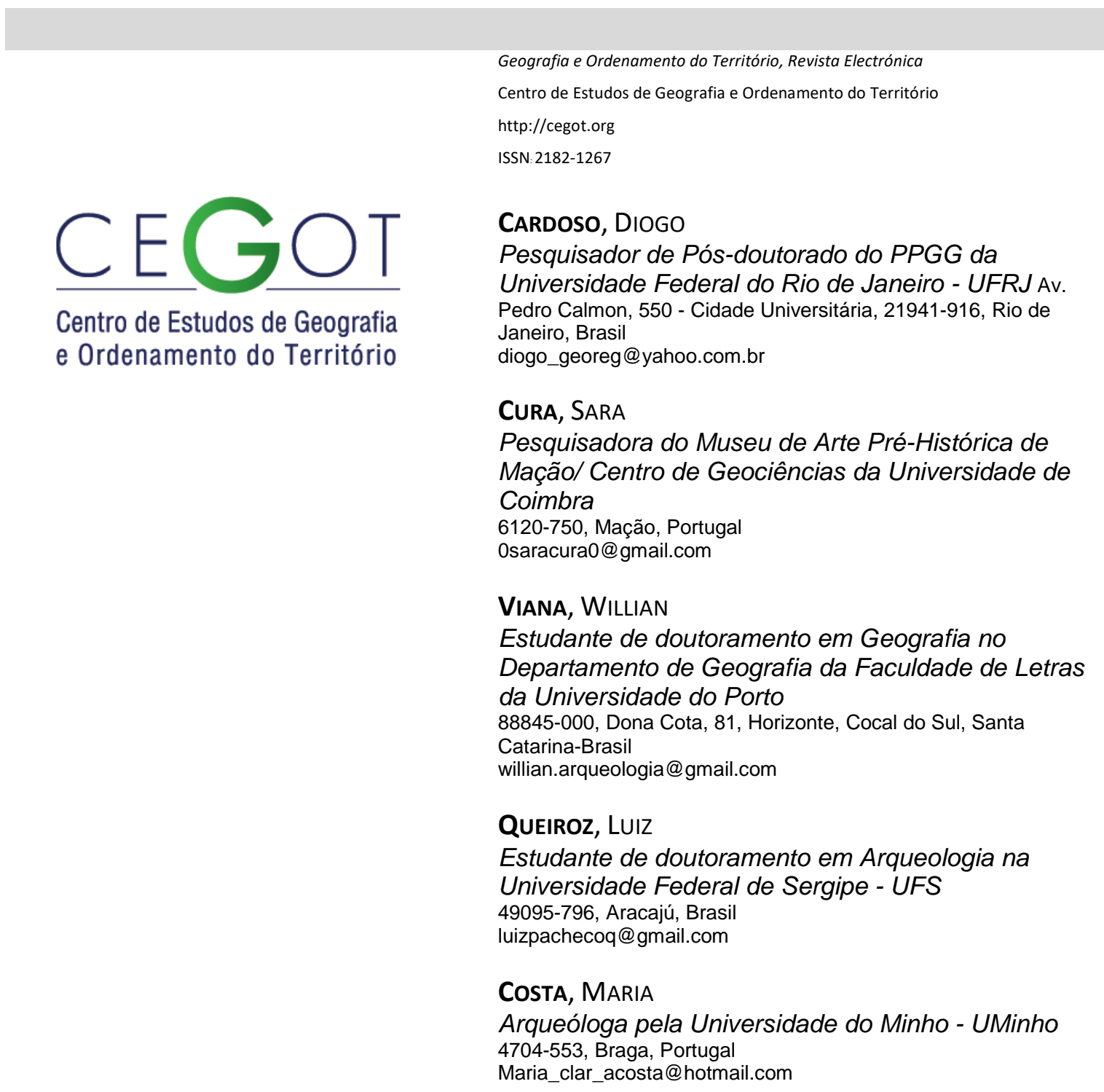

\title{
Espacialidades e ressonâncias do patrimônio cultural: reflexões sobre identidade e pertencimento
}

Spatiality and resonaces of cultural heritage: reflections on identity and belonging

Referência: Cardoso, Diogo et al. (2017). Espacialidades e ressonâncias do patrimônio cultural: reflexões sobre identidade e pertencimento. Revista de Geografia e Ordenamento do Território (GOT), n. 11 (junho). Centro de Estudos de Geografia e Ordenamento do Território, p. 83-98, dx.doi.org/10.17127/got/2017.11.004

\section{RESUMO}

Há muito tempo viemos nos perguntando qual o nosso devido lugar na natureza, e qual relação temos com a mãe Terra. Nesses termos, analisamos aqui neste escrito, mais especulativo que conclusivo, de que forma ocorre o sentimento de pertencimento; nos 
preocupando em como a temática paisagem tem se transformado num conceito-chave dentro das ciências humanas. Refletimos os emaranhados que compõem a paisagem em suas facetas, e tratamos de maneira conceitual as noções de espaço, paisagem, lugar, identidade, pertencimento, patrimônio cultural e gestão territorial. Partimos de postulados teórico-metodológicos que admitem a sociabilidade de todos, seja sociedade civil e sua concepção de mundo, seja na visão institucionalizada dos ambientes. Enfocando, sobretudo, as relações estabelecidas entre as pessoas e as materialidades externas.

Palavras-chave: gestão do território; paisagem; património cultural; lugar; identidade e pertencimento.

\section{ABSTRACT}

For a long time we have been asking what is our place in nature and our relation with mother earth. In this scope and under a more speculative than conclusive perspective we try to analyse how the feeling of belonging occurs; and looking at how the Landscape thematic is transforming itself in a key concept inside human sciences. We reflect about the tangles, which are part of the landscape, and we discuss notions of space, landscape, place, identity, belonging, cultural heritage and land management in a conceptual way. We start from a theoretical methodological postulate that admits sociability by all, either it being civil society and it conception of the world; or the environment institutionalised vision. We will focus mainly on established relations between people and external materialities.

Keywords: territory management; landscape; cultural heritage; place; identity and belonging.

\section{Introdução - Espaço e Paisagem}

A paisagem tem se transformado no conceito-chave nas ciências humanas, para tentar reverter um problema caro às sociedades modernas, com oneroso rebatimento nos ecossistemas: a desconexão e desequilíbrio das relações dos humanos com outros entes da natureza, em outros termos, com as coisas que estão no mundo. Mas, de qual natureza estamos falando? Em poucas palavras, pode-se dizer que essa nostalgia, esse anseio presente em quase todas as classes socioculturais, é uma busca incessante pelo verde, pelo ambiente pouco humanizado. Nessa procura perene por um contato libertador e purificador, pela construção de um modo de vida diferente, até mesmo o campo acaba sendo estetizado, mitificado, tornando-se um território de encontro e reencontro com o meio natural (Marques, 2008). 
O saldo dessa busca tem sido ora a implementação de políticas de contenção e parqueamento de áreas naturais para refrear a pegada ecológica, imposta pela economia capitalista; ora essa mesma natureza e ambientes físicos vem sendo reapropriados e resinificados de formas diversas, porém convergem para um ponto comum: a reelaboração criativa da relação com a mãe-terra, com Gaia, seguindo as mudanças que conduzem a proposta da pós-modernidade, as quais visam reescalonar a dimensão do humano com a esfera ecológica/geo-sistêmica, e deixando para trás a modernidade de mais de 200 anos (Vieira e Vieira, 2004, p. 15).

Sobre este último ponto, e levando em conta a atual configuração discursiva e de poder do campo ambiental brasileiro, podemos listar as iniciativas que apontam nessa direção, tais como, ecoturismo, agroturismo e outras modalidades de turismo focalizadas no patrimônio natural/ ambiental, em ecovilas, hortas comunitárias, iniciativas agroflorestais e agroecológicas, cidades verdes, empreendimentos e arquiteturas ecologicamente sustentáveis.

Em muitos dos casos, as tendências ambientalistas têm levado ao fortalecimento da identidade e das atividades no meio rural, ou mesmo levado cidades a experimentar uma ou mais atividades rurais no seu território. A introdução da agricultura em áreas urbanas e periféricas confirma a atual propensão direcionada a certa ruralização das cidades, fruto da crise econômica global e da crise de valores sobre a cidade.

Há uma tendência da evolução urbanística que procura melhorar o conforto de quem vive no espaço urbano, em simultâneo com reorganizações do espaço para ceder posição a novos lugares, que correspondem a demanda da ampliação de espaços de atividades empresariais, ou inclusão de novos, ao sabor do desenvolvimento, dos movimentos da economia e sociedade, na dinâmica capitalista, transformando as cidades a uma velocidade vertiginosa.

Nem sempre essa transformação vai ao encontro da primeira premissa, que é a de providenciar maior conforto para os habitantes; seja pela criação de espaços públicos de lazer, pela inclusão de ciclovias, novos meios do transporte público como alternativa ao dispendioso e poluente transporte automobilizado individual. Entretanto, as cidades têm 
atributos relativos à passagem do tempo (Santos, 2004), não raras as vezes, temos contrastes entre o novo e o antigo.

No Rio de Janeiro, por exemplo, é natural em vários pontos da cidade (Corredor Cultural, Copacabana, Forte de Copacabana, Leblon, Ipanema, Leopoldina, Catete, Morro da Glória, etc.) vermos uma edificação antiga sendo expremida por dois prédios modernos, um em cada lado (Carlos, 2008). Também em São Luís, estado do Maranhão, vemos o centro histório envolto por uma cidade nova.

Assim, espaço e tempo dialogam entre si, no sentido de que podemos espacializar o tempo ou temporalizar o espaço (Jorge, 2006). Contudo, espaço é também na atual sociedade capitalista uma mercadoria que se mede, compra e vende. Convém termos em mente que o espaço é também uma construção da sociedade ocidental contemporânea. Não há noção de espaço separado do ambiente natural nas sociedades ditas primitivas:

\begin{abstract}
A palavra espaço não diria nada a um aborígene australiano, a um nativo americano, ou a um ameríndio amazónico, antes de contatar com a nossa cultura. Fazendo corpo com a terra, sentindo-se elementos da terra como quaisquer outros, muitas comunidades que encontrámos pelo mundo fora tiveram dificuldade em perceber a ocupação, a utilização agressiva, a demarcação em propriedades, a exploração de algo que para eles não era uma entidade inanimada e extensa, a terra, mas uma espécie de ser parental envolvente, ontológico, que a todos produziu e a todos há de sobreviver (Jorge, 2006, p. 33).
\end{abstract}

As sensações que temos quando comtemplamos uma paisagem estão imersas de contextos relacionais, entre as pessoas e a paisagem e entre as pessoas umas com as outras, assumindo espaço e paisagens como lugares de vida. São estas relações que tornam espaços e paisagens em ambientes reconhecíveis para a construção da nossa identidade espacial.

\title{
2. Lugar e paisagem
}

O lugar é a menor unidade de todas e se trata da mais íntima do ser humano. Lugar é onde a vida acontece, local em que o sentimento de pertencimento surge ancorado, onde a memória humana se sedimenta. Um lugar é a nossa casa, o sítio no qual voltamos repetidamente, onde encontramos o conforto de uma relação afetiva e experiencial. Quando um lugar é vivenciado, a história dele é ressaltada. Se o espaço e a paisagem 
modificam o lugar, criam-se novas teias de relações dimensionais, materializam-se outros atributos e apaga-se, materialmente, parte do que ali foi vivenciado. O caráter dinâmico dos lugares pode ser observado nas intensas transformações do espaço citadino.

As cidades enredam redes narrativas, suas ruas contam histórias e fazem reaparecer memórias, num exercício que não é neutro, construindo um instrumento de afirmação política; em alguns casos anacrônicos, por encarnar mais o passado que o presente. Eventualmente, o visitante/ turista nem sempre percebe ou vivencia o local que visita, com isso não queremos dizer que este seja impossibilitade de reconhecer a autenticidade do ponto em que se encontra, longe disso. Ao passo que o cidadão residente pode transitar desatento pelo local, assimilando o ambiente mais para orientar sua própria vida, e menos para repensar a matriz do lugar (Fernandes, 2013, p. 276).

Se uma decisão institucional modifica um lugar por interesses, econômicos ou políticos, são disseminadas novas informações que podem não ter relação alguma com muitas pessoas. 0 território, enquanto parcela regida por uma gestão, recebe uma identificação que pode ser distinta do que sentem muitos indivíduos que nele habitam.

Aproximar-se, ou distanciar-se, dos novos lugares passa a ser um meio em que os sujeitos sociais terão que incorporar a sua vida, porém não apenas devido às novidades implantadas por autoridades governamentais e corporações, mas também pela própria dinâmica da cultura com suas mudanças e permanências na interação disseminada em (ou nos) ambientes construídos.

Essa ideia se consorcia com nossa opinião sobre a paisagem, que além de imagem, é um espaço de representação humana. Emerge como um espaço simbólico. É conectada à cultura e a ideia de que as formas visíveis são representações de pensamentos e discursos. Paisagens são feitas por meio de unidades reconhecíveis pelas sensações humanas, e suas características são determinadas pela organização de um sistema de significação (Cosgrove, 1998). Dessa forma, podemos dizer que a paisagem vai além do que é visível e abrange os contornos dos espaços reais, evidenciados dentro do imaginário.

É natural que grupos humanos atribuam valores e significados às estruturas edificadas, e, também, aos componentes naturais que constituem as demarcações temporais e espaciais 
(Arantes, 2008). Um exemplo que costumamos dar é o do imigrante, que quando chega a outro lugar, em outro país, por exemplo, leva conjuntos de percepções, tais como cheiros, memórias, sabores, costumes, que preenchem identificações paisagísticas. E a intimidade com os espaços socialmente construídos, mediada pelas sensações corporais, conformam o principal elemento dos lugares: a vida que os anima.

Na opinião de Matthew Johnson (2007, p. 177) o estudo social dos lugares são um tanto desonestos, fora da realidade, quando partem de visões desapegadas dos fatores emocionais. Nossa proposta de pensar, a temática em epígrafe, tem seu cerne nas concepções subjacentes à paisagem por meio da experiência sensitiva, baseadas na relação das pessoas com o ambiente. Ao refletir sobre as heranças que recebemos de outras gerações é importante dar atenção as características provenientes das noções que as pessoas constroem, com inventividade moral, estética e, sejam elas permanentes ou não, associadas à ideologia em certo período, mesmo diante de imposições mercadológicas, tais como aquelas difundidas pela especulação capitalista. Cabe dizer que, o termo mercadológico é aqui empregado como conjunto de atividades que visam orientar o fluxo de bens e serviços do local.

Em adição, o significado de paisagem não se revela somente na sua aparência, e não podemos percebê-la sem juntá-la a uma compreensão de cariz histórica, de transformação da sociedade, e com o que conseguimos visualizar de imediato. Assumir paisagens como representações culturais e também como expressão de apropriações ideológicas, políticas e turísticas, implica em refletir o movimento (Fernandes, 2013, p. 278).

Timothy Ingold (2012, p. 39 e 40) admite que toma por empréstimo o termo malha de Henri Lefebvre (1991), ao fazer uma comparação que leva a um problema epistemológico comum:

\footnotetext{
Há algo em comum, Lefebvre (1991) nota, entre o modo como as palavras são escritas numa página de texto e o modo como os movimentos e ritmos da atividade humana e não humana são registrados no espaço vivido. Mas isso apenas se pensarmos a escrita não como uma composição verbal, mas como uma malha de linhas - não como texto, mas como textura (Ingold, 2012, p. 39).
}

$\mathrm{Na}$ reflexão que aqui desenvolvemos, também, pensamos nas azinhagas reticulares "deixadas por pessoas e animais à medida que eles seguem sua vida na casa, vila e cidade. Capturando nesses múltiplos emaranhados, cada monumento ou prédio é mais arquitextural que arquitetônico, apesar de sua ilusória solidez" (...) (Ingold, 2012, p. 39). No 
atravessar portas, no andar pelas ruas, a vida vai superabundando pelos espaços vivenciados. O Mundo vaza para dentro das construções dispostas no território (Ingold, 2012, p. 40).

Tais construções ganham vida. Assim, o ser humano constrói realidades montadas em fatos interpretados, logo, a interpretação que se faz do mundo pode ser um meio de representação da realidade. Grupos humanos, de fato, agem no território. E é modificando o território que a paisagem se modifica, se intensifica, propiciando uma incursão sob a égide do sentimento de pertencer a algo, ou à algum lugar - onde o mundo acontece (Viana, Queiroz e Costa, 2016).

\section{Identidade e Pertencimento}

Numerosas são as definições das relações de pertencimento, no que tange a esfera comunitária, lugar e sentimento de pertencer à algo. Para Freitas (2008) o sentimento de pertencer a um grupo e lugar mantém a coesão comunitária, de tal modo que entrelaça o lugar, a população e o pertencer. Esses conceitos, fundamentais para a manutenção da coesão comunitária, permitem buscar entendimentos da relação sensível de apego com a paisagem.

Podemos afirmar que o sentimento de pertencimento implica em olhar e reconhecer-se. Provoca ainda pensar em si mesmo como integrante de uma sociedade que atribui símbolos e valores éticos e morais, o que destaca características culturais.

O sentimento manifestado pelos sujeitos sociais acerca do ambiente em que vivem carrega as singularidades de sua formação e encerra circunstâncias emocionais, muitas vezes, apenas vividas ali. A referida manifestação é relevante para a vida social, um sentimento que deve ser levado em consideração nos estudos e análises de comunidades (Freitas, 2008).

Indivíduos pensam em si mesmos como membros de uma coletividade, de onde emergem símbolos que expressam valores, medos e aspirações; salientando características culturais e 
étnicas. Vetores diversos podem derivar das escolhas culturais. No processo de enraizamento, por exemplo, em que se está estabelecido o sentimento de pertencimento, podem ocorrer distintas vias de seguimento ideológico e da presença das pessoas que se associam com o senso de lugar (Johnson, 2007, p. 174-180).

A formação cultural dos habitantes consolida a intimidade ou estranheza com os lugares. São sentidos opostos preponderantes e fundamentais na análise da apreciação dos lugares, que diante das transformações dos espaços sociais, se contrapõem ou se aproximam dos discursos carregados com ideias modernizadoras ou preservacionistas.

Vamos voltar à atenção para o processo dito modernizador empregado no Brasil dos séculos XIX e XX. Os principais aspectos, que o influenciaram, são as aspirações modernizadoras ao modo europeu. As possibilidades do novo e melhor habitável com a destruição do antigo atraíram os sentidos de muitas pessoas para o projeto da modernidade.

O modelo de modernização tornou inacessível a instrução do povo como um todo. Ao invés do que deveria ocorrer, e de modo anti-moderno, a população de baixa renda teve pouco acesso à educação. E com grande parte do povo iletrado e dependente das classes dirigentes, os instrumentos de dominação social se solidificaram (Canclini, 2011, p. 67-71).

Associados aos grandes planos de tornar o conhecimento acessível para poucos privilegiados, as elites brasileiras buscavam o controle social através de medidas de regulamentação do uso do espaço urbano, sem considerar a escolha dos habitantes e frequentadores dos lugares que seriam transformados. A alta sociedade praticava o que Pierre Bourdieu definiu como violência/dominação simbólica, grosso modo, uma maneira de opressão baseada na indução do (s) indivíduo (s) ao posicionamento no espaço, de acordo com as orientações do discurso dominante (Bourdieu, 2004). Ao passo que esses indivíduos subjugados, com menos ou nenhuma posse, exerciam habilidades especializadas que compunham o ambiente físico, e tornavam a sociabilidade dali única com sua presença.

A memória desses lugares é formada por ações conflituosas: tem a imposição dos donos do poder desejosos de tornar o espaço citadino semelhante a uma Europa idealizada, mas inalcançável diante da incivilidade que propunham; por outro lado é recheado de histórias de resistência e da presença dos despossuídos, marginalizados, perseguidos e tantos outros 
adjetivos negativos possíveis dados às pessoas que gostavam do seu ambiente pelas experiências ali vivenciadas, mas que estavam alheias ou não tinham como lutar contra aquelas ideias disseminadas para sua domesticação.

Para quem tinha relação com os espaços urbanos já existentes, aos que gozavam do meio social pleno de significados culturais, a manutenção das paisagens não era somente uma questão de lembranças dos tempos vividos. A modificação do casario antigo, dos becos e vielas representaria o fim dos lugares utilizados nas atividades lúdicas, nas celebrações profanas e religiosas, na labuta pelos ganhos diários, dentre tantas manifestações cotidianas.

A manipulação do território-paisagem, por vias tortuosas da representação da civilização, é também a destruição dos elementos que ligavam os agentes sociais aos lugares criados pelo processo de enraizamento. A desterritorialização desmaterializou suas práticas diárias de vida e rompeu os sentimentos de pertencimento com o lugar.

Nos centros urbanos de várias cidades brasileiras, de meados do século XIX ao início do século $\mathrm{XX}$, esse quadro é parte de sua história. Por exemplo, o comércio de ambulantes, os rituais religiosos e a vida boêmia foram impactados diretamente pelas rápidas mudanças.

Por trás de projetos de melhoramentos de vias existiam tentativas de expulsão e/ou o adestramento das classes consideradas baixas.

As ações, para tanto, direcionadas pela sociedade letrada, participantes ativas do debate da urbanização, higienização e teoria de branqueamento da população (eugenismo), propunham uma imagem de cidade enquanto centro urbano exemplar. E o lugar que existia para as comunidades que foram retiradas deles, expropriadas e sem direito a opinião, ganhou uma lacuna, perdeu o sentido. A desestruturação criada pelos projetos progressistas de desenvolvimento urbano deu o tom de desapego com o novo edificado, que deixou de ser notícia futura e tornou-se realidade insignificante para esses últimos.

As escolhas dos cidadãos, independentemente de sua situação social, mostram como novos sentimentos fluíam a partir da formação de paisagens com a demolição de edificações para conformar arruamentos. As ideias ditas civilizatórias representam uma soberba e notória atitude de destruição do patrimônio associada com ideais modernizantes. Contudo, para as 
pessoas que conviviam no lugar, e faziam dele vivo, a conservação dos espaços urbanos era urgente.

Paisagens modernistas foram criadas, mas não absorvidas por todos. As transformações do espaço urbano, ao apagar memórias, destruíram vidas e a possibilidade de experiências, além disso, formou novos ambientes, com outras redes relacionais, e com valores, em alguns casos, representando a sensibilidade de uma minoria.

As divergentes e variadas ideias dos séculos XIX e XX mostram como estão associados ao patrimônio edificado noções da presença de pessoas consideradas repugnantes por parcela da sociedade. O espaço citadino, pensado como o lugar organizado, ou melhor, idealizado para o aproveitamento apenas de alguns, destaca uma faceta de grupos sociais que queriam reunir a posse de importantes áreas urbanas em suas mãos. Para além dos efeitos mnemônicos negativos de tal atitude, a construção da paisagem através da remodelagem de centros urbanos mostra as contradições dos pensamentos dos períodos em destaque. Contradições também marcadas pelos discursos e metanarrativas em voga.

É importante falarmos sobre as contradições de nossa história quando voltamos olhares para a paisagem, que também é permeada pelas pessoas que atuam nela. É pensada com os indivíduos, com a presença deles.

Essas intricadas noções dão-nos conta da dimensão paisagística intrínseca à sensibilidade de muitas pessoas, influenciadas pelas maneiras de pensar do seu tempo e lugar. De modo contrário pensa Bourdieu (1990, p. 158), pois sua concepção parece ir contra a fenomenologia, ao considerar que os agentes constroem sua visão de mundo sob coações estruturais. Assim, as representações dos agentes variam em conformidade com sua posição e com seu habitus, como estruturas cognitivas e avaliatórias que eles adquirem através da experiência durável de uma posição social. 


\section{Patrimônio Cultural}

O patrimônio cultural está imerso nos temas precedentes, faz parte da paisagem enquanto alcance humano, integra o território e Ihe confere identidade. Está no lugar em que se vivencia a culturalidade na sua integralidade:

Gasto das múltiplas visitações, normalmente repetitivas, que lhe fazemos (discurso da perda, da incompreensão dos outros, das evidencias indiscutíveis, das descrições exaustivas, do exotismo dos costumes, do pitoresco das particularidades em fim, etc., etc.). Novo, porque sendo um conceito envolvente que tem a ver com tudo o resto, é sempre passível de novas reflexões e leituras, com que incansavelmente vamos querendo abraçá-lo numa suposta essencialidade, que é evidentemente mítica (Jorge, 2003, p. 11).

O património não é uma essência, nem um valor atemporal - é uma invenção da sociedade contemporânea. Logo para o entendermos (nos seus benefícios e nos seus malefícios), para o perceber com sintoma, é preciso reportar à sociedade contemporânea no seu todo (Jorge, 2005, p. 52).

O patrimônio, como bem coletivo, é uma construção do presente, de um presente que tende a fugir para o passado e para o futuro. Não faz sentido dizer que o passado e o patrimônio não existiram, ou falar deles como algo acontecido. Não devemos falar deles como forma de representação, mas falar deles tendo em consideração os regimes do seu fabrico, como algo indispensável à visa cotidiana das sociedades modernas.

O património, saído de um dos paradoxos da modernidade (quebrar a ordem antiga, mas recuperar a sua herança para usufruto de todos) tanto pode ser uma forma de opressão (uma força contra a criatividade e a partilha), como de libertação (um instrumento de criatividade e não de segregação). (...) compete-nos a nós escolher, discutindo para que serve conservar, que discursos vamos construir a partir disso que dizemos conservar, que documentos vamos deixar para que o futuro possa ajuizar da maior ou menor justeza, do maior ou menor rigor, desses discursos (Jorge, 2005, p. 60).

Nos últimos anos, a ideia de salvaguardar o patrimônio cultural vem ganhando destaque como algo relevante. Mais ainda quando se redescobre as capacidades do patrimônio cultural. Há, então, um direcionamento de perspectiva por parte das instituições em relação aos centros antigos, bens culturais edificados. Se por um lado há preocupação, por outro lado essas instituições intervêm, de modo a tentar criar a qualquer preço uma imagem que estimule o interesse da população. Mesmo que sugira querer apagar as imagens negativas do passado, ou, em outros casos, instaurar novas paisagens (Silva, Falcão e Barbosa, 2011, p. 61). Aqui temos de tomar particular atenção ao fato de não podermos reivindicar um 
congelamento de paisagens e territórios como representativos de patrimônio, que se transformassem em museus ou parque temáticos a servir a indústria do turismo.

A patrimonialização de um objeto, enquanto ato administrativo realizado pelo poder público com o objetivo de preservar, é entendida como um ato legítimo de reconhecimento do seu valor histórico-cultural. Concepções enraizadas no modernismo têm contribuído amplamente para a perda da memória e, num movimento inverso, torna a patrimonialização um processo anacrônico, incoerente e insustentável.

Deste modo há atuação da ideia de valorização do novo e descaracterização do velho, comum à oposição entre objeto e sujeito, natureza e cultura - binaridades do pensamento moderno que conceberam o mundo como imagem e objeto, além de tornarem os seres humanos ativos observadores, producentes de mudanças nos elementos materiais passivos. Baseia-se aí a ideia da paisagem como pintura, fenômeno da sensibilidade moderna, que distancia o mundo da participação humana, como mercadoria produzida e consumida por sujeitos (Thomas, 2001, p. 168).

Uma das causas dessa incoerente e desenfreada patrimonialização são os ditos melhoramentos que alavancam as transformações de espaços urbanos, e que têm sido cada vez mais intensos desde 1920, nos centros históricos das capitais estaduais brasileiras, como, por exemplo, a demolição da Igreja da Sé em Salvador para o alargamento de uma via e maior fluxo de automóveis na década de 1940 - sinônimo de progresso na época. Outros exemplos pertinentes ao que gostaríamos de demonstrar:

Nos anos 1930, a Avenida Central no Rio de Janeiro, atual Rio Branco, era uma versão tropical da parisiense Champs-Élysées, tomada por prédios ecléticos de influência francesa. Havia exemplares belíssimos, como o Hotel Avenida, com seus 220 quartos de luxo, e o imponente Palácio Monroe, primeiro projeto brasileiro a ganhar um prêmio internacional de arquitetura. Nessa mesma época, em São Paulo, ao longo da Avenida Paulista, espalhavam-se palacetes construídos por imigrantes europeus. Prósperos, reproduziam a linguagem arquitetônica de seus países de origem. Em Salvador, bairros como o Corredor da Vitória eram tomados por charmosos edifícios neoclássicos. Tudo isso foi abaixo, e não apenas por culpa da especulação imobiliária. A desfiguração dessas e de outras capitais brasileiras aconteceu com a complacência e o apoio de quem deveria preservá-las. O Serviço do Patrimônio Histórico, atual Iphan, criado em 1937, tinha à frente um grupo de modernistas, influenciado pelo arquiteto Lúcio Costa. O grupo detestava a arquitetura eclética. Para eles, o verdadeiro estilo brasileiro era o colonial, abundante nas cidades históricas mineiras e nas igrejas barrocas do Rio e Salvador. Esse pensamento ajudou a construir uma visão parcial do passado brasileiro, em que não cabiam prédios ornamentados, de influência francesa (Bortoloti, 2015). 
Joachim Hermann (1989, p. 36) sugere que a consciência histórica é intimamente associada aos patrimónios arqueológicos e arquitetônicos. Através do ato de conservação da cultura material empregamos sentidos e significados, constituindo a materialização da identidade local, estadual e nacional. Contudo, a disparidade de opiniões entre as instituições, de destaque e peso, e a própria população abre espaço para que haja discussões acerca do que deve ser ou não patrimonializado e conservado.

Verifica-se que o uso e o discurso do patrimônio, na sociedade contemporânea, são acompanhados de sentimento de perda e reclamação. O patrimônio é um bem a que não se dá a devida atenção, estando inexoravelmente em permanente desgaste, seja por omissão das autoridades ou por falta de consciência cívica e cultural das populações.

No Brasil, tal como em toda a América Latina, a política de preservação começou com o manejo patrimonial de antigas igrejas coloniais. O que mais se destaca nesse início é a importância da Igreja Católica na colonização ibérica do Novo Mundo (Funari, 2001). Contudo no Brasil o anseio das elites pela modernização, acabou por decretar o destino de vários edifícios históricos. Aqui está o exemplo do aproveitamento político nacional que utilizou o patrimônio como dispositivo auto-legitimador.

Um problema maior consiste na falta de manutenção dos monumentos tombados. Podemos relacionar esse descaso tanto por parte do governo, como por grande parte da população com a falta de identificação para com os monumentos escolhidos. Como diz Fernandes (1993, p. 275) houve uma política de patrimônio que preservou a casa-grande, as igrejas barrocas, os fortes militares, as câmaras e cadeias como as referências para a construção de nossa identidade histórica e cultural, e que relegou ao esquecimento as senzalas, os quilombolas, as favelas, os bairros operários e os testemunhos arqueológicos pré-históricos. Isso é devido ao início da implementação da política patrimonial no país, relegada a escritores, arquitetos e artistas, representantes das classes mais abastadas, e não a arqueólogos e historiadores (Munari, 1995 apud Funari, 1998).

Segundo Byrne (1991, p. 275) pode se considerar normal grupos dominantes usarem seu poder para promover o seu próprio patrimônio, minimizando ou mesmo renegando a importância de grupos subordinados ao forjar uma identidade nacional à sua própria 
imagem. Assim, conseguimos compreender o porquê da renegação da proteção patrimonial por grande parcela da população, sentida como se fosse estrangeira.

O amadurecimento de uma nova perspectiva sobre a nossa história percorreu um longo caminho até meados dos anos 80 , quando começamos a ver esboços mais populares e democráticos. Claro que o maior acesso ao ensino superior da parcela mais pobre da população, ajudou na formação de mais pesquisadores em patrimônio, isto é, interessados na preservação da história de grupos subalternos.

\section{Considerações Finais}

A forte crença do domínio da natureza pelos seres humanos (Tuan, 2012, p. 1) é um aspecto primordial na abordagem da manipulação do patrimônio cultural e que é plausível de ser discutido através da relação das pessoas com os lugares. Porém, outros fatores são decisivos para avaliar como ocorrem as mudanças na paisagem, tais como o uso da ciência em benefício do progresso, mola propulsora de desenvolvimento já em corrente uso desde o século $X X$.

No âmbito da ação de instituições, públicas e privadas, sobre o patrimônio cultural, todas as pessoas podem opinar acerca das políticas de preservação. Porém é evidente que a participação popular não é notória, tem atuação reduzida e, diante da força das corporações mundiais, não têm tido grandes chances de contribuir para reverter processos, que desagregam a preservação da memória. Dentro do contexto em que atuam, podem tornar significantes suas atitudes diante dos lugares que constroem. Decisões feitas dentro de tais instituições, e sem a consulta popular, não têm a tendência de resultar em soluções para a manutenção da memória da história local.

Uma grande soma de meios que levam a transformações da paisagem não tem como proposta o respeito às comunidades locais. Esse é o exemplo de obras localizadas em bairros, grandes avenidas e ruas das cidades que rompem com a preservação de edificações históricas, bem como a construção de grandes empreendimentos que avançam pela zona rural e provocam a destruição de parcelas significantes do meio físico, histórico e 
arqueológico; provocando também a extinção de espécies da fauna, flora, nascentes e cursos d'água.

As regras ditadas pela economia mundial são decisivas para o que merece ou não ser preservado. A porção Ocidental do Planeta é influenciada por essas orientações políticoeconômicas. A percepção histórica da paisagem tem que lidar com as novidades que surgem do movimento de construção e reconstrução, que somente aparentam trazer fluidez e arejamento, mas que levam sim ao caos mnemônico. Como resultado ocorre uma gritante mudança com a perda de identidade das pessoas com os lugares presentes em suas sensações.

O patrimônio arqueológico engloba outra realidade, já que consegue representar a parcela histórica excluída pela a política de patrimonialização. Com os trabalhos perpetuados nos sítios arqueológicos, conseguimos retirar evidencias materiais para elaborar estudos dessas populações marginalizadas pelo registro histórico. Tal como pudéssemos dar voz a aqueles que nunca tiveram.

\section{Referências bibliográficas}

ARANTES, Antônio Augusto. Patrimônio Cultural: desafios e perspectivas atuais. Curso: Patrimônio Imaterial Política e instrumento de identificação, documentação e salvaguarda. Belo Horizonte: DUO Informação e Cultura, 2008.

BERTRAND, Georges. Paisagem e Geografia Física Global. In: Revista RAEGA - O Espaço Geográfio em Ação. Curitiba: Editora UFP, número 8, 2004, p. 141-152.

BOURDIEU, Pierre. Coisas ditas. São Paulo: Editora Brasiliense, 1990, 235 p.

BOURDIEU, Pierre. O poder simbólico. Rio de Janeiro: Editora Bertrand Brasil, 7 ed., 2004, 314 p.

BYRNE, Denis. Western hegemony in archeological heritage management. In: History and Anthropology, 1991, p. 269-276.

BORTOLOTI, Marcelo. Demolição de prédios históricos motivada por arquitetos modernistas. Rio de Janeiro: Revista Época/Globo, 2015. Disponível em: <http://epoca.globo.com/ideias/noticia/2015/03/bdemolicao-depredios-historicosb-foi-motivada-por-arquitetos-modernistas.html>. Acessado em: 20.04.2017.

CANCLINI, Néstor García. Culturas Híbridas - estratégias para entrar e sair da modernidade. Tradução de Ana Regina Lessa e Heloísa Pezza Cintrão. São Paulo: EDUSP, 1997, p. 283-350. ISBN 978-85-314-0382-8.

COSGROVE, Denis Edmund. Social Formation and Symbolic Landscape. Madison: University of Wisconsin Press, 1998. ISBN 0-299-15514-5.

FERNANDES, João Luís. Paisagem cultural: de um espaço de reterritorialização a um recurso turístico. The Overarching Issues of the European Space. Porto: Ed. Faculdade Letras da Universidade do Porto, 2013. 
FERNANDES, José Ricardo Oria. Educação Patrimonial e cidadania: uma proposta alternativa para o ensino de história. In: Revista Brasileira de História, volume 13, número 25/26, 1993, p. 265-276.

FREITAS, César Gomes. Desenvolvimento local e sentimento de pertença na comunidade Cruzeiro do Sul - Acre. Dissertação de Mestrado em Desenvolvimento Local. Campo Gande: Universidade Católica Dom Bosco - UCDB, 2008.

FUNARI, Pedro Paulo. Cultura Material e Histórica. Campinas: Instituto de Filosofia e Ciências Humanas / Universidade Estadual de Campinas - UNICAMP, Coleção, Primeira Versão número 120, 1998, 62 p. ISSN 16767039.

FUNARI, Pedro Paulo. Os desafios da destruição e conservação do património cultural no Brasil. Porto: Revista Trabalhos de Antropologia e Etnologia, vol. 41, 2001, p. 23-32. Disponível em: <http://www.unicamp.br/nee/arqueologia/arquivos/arq hist estrat/desafios.html\# ftn1>. Acessado em: 20.04.2016.

HERMANN, Joachim. World Archeology - The world's cultural heritage. In: CLEERE, H. F. Archeological Heritage Management in the Modern World. London: Unwin Hyman, 1989, p. 30-37.

INGOLD, Timothy. Trazendo as coisas de volta à vida: emaranhados criativos num mundo de materiais. Porto Alegre: Horizontes Antropológicos, ano 18, n. 37, 2012, p. 25-44.

JOHNSON, Matthew. Ideas of Landscape. United Kingdom: Blakcwell Publishing, 2007, 266 p. ISBN 9781405101608.

JORGE, Victor Oliveira. A Irrequietude das Pedras: Reflexões e experiências de um arqueólogo. Porto: Edições Afrontamento, 2003, 193 p. ISBN 972-36-0696-8

JORGE, Victor Oliveira. Fragmentos, Memórias, Incisões: Novos contributos para pensar a arqueologia como um domínio da cultura. Lisboa: Edições Colibri, 2006. ISBN 978-97-277265-78.

JORGE, Victor Oliveira. Vitrinas muito iluminadas. Porto: Campo das Letras, 2005.

MARQUES, Hélder Trigo Gomes. Porquê (e razões para) a mitificação do campo. Coimbra: Comunicação apresentada no VII Colóquio Ibérico de Estudos Rurais - Cultura, Inovação e Território, 2008.

LEFEBVRE, Henri. The production of space. Tradução de Donald Nicholson Smith. Cambridge/ Massachussets: Basil Brackwell Editor, 1991, 454 p. ISBN 0-631-14048-4.

MILLER, Tom. Considerações sobre a tecnologia: quando é um artefato? In: Vivência - Revista de Antropologia, volume 1, número 39, 2012, p. 91-100.

SANTOS, Milton. Pensando o Espaço do Homem. São Paulo: EDUSP, 2004, 90 p. ISBN 978-85-314-0835-9.

SILVA, Georgia Patrícia da; FALCÃO, Márcia Teixeira.; BARBOSA, Maria Aparecida. F. O Caso e o Descaso: 0 Patrimônio Cultural da Cidade de Boa Vista-RR. In: CULTURA - Revista de Patrimônio e Turismo, ano 5, n. 02, 2011. Disponível em: $\langle$ http://www.uesc.br/revistas/culturaeturismo/ano5-edicao2/artigo 4.pdf $>$. Acessado em: 27.04.2016.

THOMAS, Julian. Archaeologies of place and landscape. In: Hodder, Ian (ed.) Archaeological Theory Today. Cambridge: Polity, 2001, p. 165-186. ISBN: 978-0-7456-5306-8

TUAN, Yi-Fu. Topofilia: um estudo da percepção, atitudes e valores do meio ambiente. Londrina: Eduel Editora, 2012, 250 p. ISBN 978-8572166270.

VIANA, Willian Carboni; QUEIROZ, Luiz Antonio Pacheco de; COSTA, Maria Clara Rocha. Formação ideacional da paisagem e as contribuições da Arqueologia e da Geografia. Revista on-line Sodebras, volume 126, 2016, p. 31-36. Disponível em: <http://www.sodebras.com.br/edicoes/N126.pdf>. Acessado em: 20.04.2017.

VIEIRA, Euripedes Falcão; VIEIRA, Marcelo Milano Falcão. A dialética da Pós-modernidade: a sociedade em transformação. Rio de Janeiro: Fundação Getúlio Vargas Editora, 2004, 192 p. ISBN 85-225-0490-3. 